\title{
Risk Assessment of Flood Disaster Based on Set Pair Analysis and the Variable Fuzzy Set Theory in Yuquan District, Hohhot City
}

\author{
Ren Bu ${ }^{1,2}$, Enliang Guo ${ }^{1,2}$, Mandula Naren ${ }^{1,2}$ \\ ${ }^{1}$ College of Geographical Science, Inner Mongolia Normal University, Huhhot 010022, China \\ ${ }^{2}$ Inner Mongolia Key Laboratory of Disaster and Ecological Security on the Mongolia Plateau, \\ Huhhot 010022, China
}

\section{基于集对分析与可变模糊集的呼和浩特市玉泉 区暴雨洪涝灾害风险评价研究 布仁 ${ }^{1,2}$, 郭恩亮 ${ }^{1,2}$, 那仁满都拉 ${ }^{1,2}$ \\ 1 内蒙古师范大学地理科学学院, 内蒙古 呼和浩特, 010022 , 中国}

2 内蒙古自治区蒙古高原灾害与生态安全重点实验室, 内蒙古 呼和浩特, 010022, 中国

\begin{abstract}
This study presents the methodology and procedure for risk assessment of flood disasters in Yuquan district, Hohhot City, which was supported by technology of natural disaster risk assessment. On the basis of the standard formulation of natural disaster risk and flood disaster risk index, of which weights were developed using combined weights of entropy, the relative membership degree functions of variable fuzzy set (VFS) theory were calculated using set pair analysis, while level values were calculated using VFSs, including hazard levels, exposure levels, vulnerability levels and restorability levels, and the flood risk level for each assessment unit that is $100 \mathrm{~m} \times 100 \mathrm{~m}$ was obtained using the natural disaster index method. The results show that The regions with extremely high risk and high risk are mainly located in the northeast and central regions, and the
\end{abstract}

proportions of the occupied areas are 3.86\% and $7.16 \%$, respectively; The study can provide scientific reference in flood risk management for local and national governmental agencies.

Keywords: Flood disasters; Risk assessment; Set pair analysis; Variable fuzzy sets; Yuquan District

\section{摘要}

本文根据自然灾害风险形成原理, 结 合自然条件和社会经济情况, 从危险性、 暴露性、脆弱性和防灾减灾能力 4 个方面 出发构建洪涝灾害风险评价指标体系, 并 且制定相应指标的评价标准; 以 $100 \mathrm{~m} \times 100 \mathrm{~m}$ 网格单元为基本评价单元, 采 用集对分析法计算评价评价单元各指标与 评价等级之间的联系度, 运用熵组合权重 确定各指标的权重, 然后利用可变模糊集 理论计算评价单元的危险性等级、暴露性 等级、脆弱性等级和防灾减灾能力等级, 
最终通过构建的城市暴雨洪涝灾害风险评 价模型, 对呼和浩特市玉泉区暴雨洪涝灾 害风险进行评价, 结果表明: 极高风险和 高风险等级区域主要是位于东北和中部地 区, 所占面积比例分别为 $3.86 \%$ 和 $7.16 \%$, 该研究结果可以作为呼和浩特市玉泉区洪 涝灾害管理的理论依据。

关键词：洪涝灾害；风险评价；集对分 析; 可变模糊集; 玉泉区

\section{1. 引言}

二十世纪以来, 随着人口的急剧上升 和经济的快速发展, 原有的孕灾环境和致 灾因子不断外延和激化, 造成新的灾种和 致灾因子不断产生, 相伴而生的自然灾害 发生频率和强度也随之不断增强 [1]; 其 中, 从发生频率、造成的人员伤亡及经济 损失、灾害发生的时空强度及对人类文明 的威胁程度而言, 洪涝灾害皆居于各种自 然灾害之首[2]。据 1951 2000 年资料统 计, 我国平均每年洪涝受灾面积为 $9.35 \times 104 \mathrm{~km} 2$, 是遭受洪涝灾害比较严重的 国家之一[3], 近年来, 由于呼和浩特市人 口激增, 加之城市“热岛效应” 凸显, 地下排 水设施是是直埋式管网, 暴雨发生后极易 引起城市内涝灾害, 对于当地社会经济发 展带来了严峻的挑战。因此, 开展该地区 的洪涝灾害风险分析对于有效减免灾害损 失具有重要意义。

洪涝灾害风险分析是洪涝灾害风险管 理的基础性工作, 是科学有效地防洪减灾 的重要决策依据, 一直是国内外灾害学研 究的热点和难点问题。国际上对于洪涝灾 害风险的研究主要分为定性评估和定量评 估, 其中定性评估是使用系统工程方法, 将系统进行分解, 依靠人的观察分析能 力, 借助有关法规、标准、规范、经验和 判断能力进行评估。定量评估是在对风险 因子量化的基础上进行的评估, 主要有概 率风险评价法和综合风险指数法 [4]。其中 概率风险评价法是指依靠洪涝灾害的历史 统计数据, 运用数学方法构造数学模型进 行评估。例如, Fernandez, E 等基于历史灾 情数据创新性的提出了利用间隔(范围)、模
糊集和权重确定灾情等级和重现期[5]。 $\mathrm{Li}$, $\mathrm{Q}$ 采用可变模糊集 (VFS) 和改进的信息扩 散法（IIDM）相耦合的综合方法, 利用受 灾面积、死亡人数、倒塌房屋等历史灾情 数据对洪水风险进行了分析 [6]。Ji Z, Li N 等通过建立分类与回归树模型对区域洪涝 进行了风险评价[7]。综合风险指数法是通 过选取影响洪涝灾害风险的关键指数, 建 立洪涝灾害风险综合指数模型进行评估。 洪涝灾害风险受致灾因子、孕灾环境及承 灾体等众多不确定因素影响, 而且表达这 些因素的地理信息、遥感信息以及统计信 息本身就存在多重性、复杂性、不确定 性。针对这一特点, 一些不确定性的方法 和理论被用于洪涝灾害风险评估中, 例 如, 蒙特卡罗法 [8,9], 神经网络法 [10, 11], 模糊评价法[12], 集对分析[13]和可变 模糊集理论[14]等, 并且取得了一些成果, 但是不能很好的处理灾害系统中信息的模 糊和不确定性问题, 比如神经网络存在学 习收敛速度慢、容易陷入局部极小点而无 法得到全局最优解等缺点。模糊评价法对 客观隶属函数难以确定, 并且不能很好地 解决所造成的相关评价指标的信息重复问 题。可变模糊集理论计算过程复杂和繁 琐, 并且在计算隶属度时过分的依赖专家 的主观经验。集对分析法则存在着结果容 易向相邻评价等级转换的趋势, 造成判断 结果失真。因此, 对于各种方法进行有机 的组合或相互补充, 形成新的方法是另一 种日益增长的趋势。将集对分析法和可变 模糊集理论进行有机的耦合, 可以解决两 种方法各自存在的问题。具体来说就是利 用集对分析法计算的相对隶属度解决可变 模糊集自身隶属度物理主观性的缺点, 等 级结果评判时利用可变模糊集解决等级判 断失真的问题。本文具体的评价过程为: 以五级评判为原则, 利用集对分析法分别 计算评价单元的危险性、暴露性、脆弱性 和防灾减灾能力与评价等级之间的联系 度, 运用熵组合权重法确定各指标的权 重, 然后利用可变模糊集理论计算得到各 评价单元的危险性等级、暴露性等级、脆 弱性等级和防灾减灾能力等级。最终通过 
洪涝灾害风险评价模型, 计算评价单元所 属的洪涝灾害风险等级。

\section{2. 研究区概况}

玉泉区是内蒙古自治区呼和浩特市四 大城区之一。位于呼和浩特市的中部地 区, 市区的西南部。东与赛罕区相邻, 南 部和西部与土默特左旗接壤, 北与回民区 毗连。气候属温带大陆性季风气候, 四季 气候变化明显, 年温差大, 日温差也大, 年平均气温在 $6^{\circ} \mathrm{C}$ 左右。由于城市地势低 洼, 容易引起城市内涝灾害[15]。
自然灾害风险 $=f$ (危险性, 暴露性, 脆弱 性, 防灾减灾能力)

$$
=H \cap E \cap V \cap R
$$

其中, $\mathrm{H}$ 表示危险性, $\mathrm{E}$ 表示暴露性, $\mathrm{V}$ 表 示脆弱性, $\mathrm{R}$ 表示防灾减灾能力。

(2) 集对分析法

集对分析法(Set Pair Analysis, SPA)是 一种描述和处理不确定性系统的综合分析 方法, 主要是将不确定性系统中的两个有

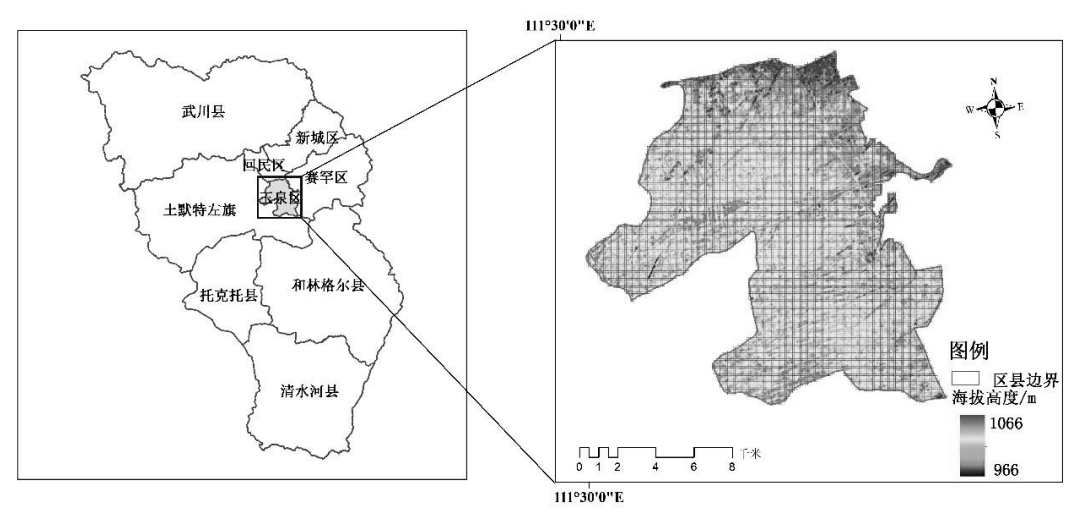

图 1. 研究区地理位置及格网示意图

\section{3. 数据来源及研究方法}

\section{1 数据来源}

气象数据来自于中国区域高时空分辨 率地面气象要素驱动数据集 (ITPCAS CM FD), 水平空间分辨率 为 $0.1^{\circ}$, 经过处理 提取逐日降水量; 路网数据来自于 openstre etmap (https://www.openstreetmap.org/), A STER GDEM V2 全球数字高程数据来自于 地理空间数据云, 人口数据和社会经济数 据来自于呼和浩特市统计年鉴。

\section{2 研究方法}

（1）自然灾害风险形成理论

自然灾害风险指未来若干年内可能达到 的灾害程度及其发生的可能性。一般而 言, 某一地区的自然灾害风险是危险性、 暴露性、脆弱性和防灾减灾能力四者相互 作用的结果。即:
关联的集合构造为集对, 通过同一性、差 异性和对立性分析构建改进改进集对分析 的同异反联系度, 从而全面刻画系统内部 之间的同、异、反联系, 得到更加贴近客 观实际的研究结果 [16]。

\section{(3) 可变模糊集理论}

可变模糊集理论是在工程模糊集理论基 础上发展起来的理论体系, 主要是运用自 然辩证法中关于运动的矛盾性原理, 提出 事物具有对模糊概念吸引性质的相对隶属 度与排斥性质的相对隶属度。然后根据对 事物边界的描述, 确定对立模糊集。在此 基础上可以进一步确定相对差异函数、相 对比例函数和模糊可变集合。最终在已知 标准区间范围的情况下, 根据公式和模型 求解出隶属于某一区间或等级的相对隶属 度, 进而确定评价等级 [17]。具体构建思路

（4）熵组合权重法 
层次分析法(AHP) 是一种对指标进行定 性定量分析的方法, 是主观确定指标权重 的方法之一; 熵值法是根据所求熵值对于 指标的离散程度确定各指标的权重的方 法, 是一种客观确定权重方法; 为了克服 人为确定权重的主观性, 将层次分析法与 熵值法结合确定各指标的权重[18]。

$$
W_{j}=\frac{\sqrt{W_{1 j} \times W_{2 j}}}{\sum \sqrt{W_{1 j} \times W_{2 j}}}
$$

式中: $W_{j}$ 为 $j$ 指标的综合权重; $W_{1 j}$ 为指标 $j$ 的主观权重; $W_{2 j}$ 为指标 $j$ 的客观权重。

\section{4. 洪涝灾害风险评价指标体系与模型的 建立}

\section{1 洪港灾害风险评价指标体系的建立}

由于构建洪涝灾害风险评价体系的方 法众多、指标多样, 因此是一项复杂的工 作。在分析玉泉区地理特征的基础上, 依 据洪涝灾害风险的相关原理, 遵循科学 性、可操控性等原则从危险性、脆弱性、 暴露性和防灾减灾能力四个层面选取评价
指标, 最后选取多个指标建立玉泉区洪涝 灾害风险评价的指标体系, 用于评价洪港 灾害风险的大小程度, 在本研究中, 主要 是利用核密度分布计算相应指标的空间分 布。

\section{2 评价等级标准及指标权重的确立}

在引用相关文献中确定标准的方法基 础上, 结合研究区自然地理、水文气象条 件、社会经济及其对洪涝灾害影响的实际 情况和特点, 确定各项评价指标的分级标 准, 确定指标权重时, 首先通过对多位专 家的咨询, 把各指标按照相对重要程度进 行九分位打分, 通过专家打分构造判断矩 阵计算出各指标的权重, 并且危险性、暴 露性、脆弱性和防灾减灾能力的一致性比 例分别为 $0.0945 、 0.0176 、 0.0694$ 和 0.0519, 皆通过了一致性检验。然后利用公 式进行指标熵权重的计算, 最后根据公式 计算各指标的组合权重, 结果见表 1 。

表 1. 洪涝灾害指标权重及等级标准

\begin{tabular}{|c|c|c|c|c|c|c|}
\hline $\begin{array}{c}\text { 洪涝灾害 } \\
\text { 四因子 }\end{array}$ & $\begin{array}{c}\text { 等级标 } \\
\text { 准 } \\
\end{array}$ & 1 级 & 2 级 & 3 级 & 4 级 & 5 级 \\
\hline 危险性 & $\begin{array}{c}\text { 年降水 } \\
\text { 量 }\end{array}$ & $(341.01,343.52]$ & $(343.53,343.94]$ & $\begin{array}{l}343.95, \\
344.44]\end{array}$ & $(344.45,345.12]$ & $(345.13,347]$ \\
\hline \multirow[t]{4}{*}{$(0.3296)$} & $\begin{array}{l}\text { 极端降 } \\
\text { 水频率 }\end{array}$ & $(0,2.07]$ & $(2.07,3.15]$ & $(3.15,3.5]$ & $(3.5,3.85]$ & $(3.85,4.50]$ \\
\hline & 高度 & $(1033,1066]$ & $(1024,1032]$ & $(1016,1023]$ & $(1006,1015]$ & $(966,1005]$ \\
\hline & $\begin{array}{l}\text { 高程标 } \\
\text { 准差 }\end{array}$ & $(0,1.97]$ & $(1.98,3.15]$ & $(3.16,4.56]$ & $(4.57,6.64]$ & $(6.65,14.4]$ \\
\hline & $\begin{array}{c}\text { 河网密 } \\
\text { 度 }\end{array}$ & $(0,0.255]$ & $(0.256,0.358]$ & $(0.359,0.445]$ & $(0.446,0.542]$ & $(0.543,0.721]$ \\
\hline 暴露性 & $\begin{array}{c}\text { 人口密 } \\
\text { 度 }\end{array}$ & $(0,0.02]$ & $(0.02,0.03]$ & $(0.03,0.06]$ & $(0.06,0.14]$ & $(0.14,0.32]$ \\
\hline$(0.2587)$ & $\begin{array}{c}\text { 经济密 } \\
\text { 度 }\end{array}$ & $(48.1,3510]$ & $(3520,8800]$ & $(8810,15700]$ & $(15800,25700]$ & $(25800,46500]$ \\
\hline $\begin{array}{l}\text { 脆弱性 } \\
(0.2417)\end{array}$ & $\begin{array}{l}\text { 中小学 } \\
\text { 校密度 }\end{array}$ & {$[1.04,1.55)$} & {$[0.61,1.03)$} & {$[0.299,0.609)$} & {$[0.0915,0.298)$} & {$[0,0.0914)$} \\
\hline $\begin{array}{c}\text { 防灾减灾 } \\
\text { 能力 }\end{array}$ & $\begin{array}{c}\text { 路网密 } \\
\text { 度 }\end{array}$ & $(0,0.56]$ & $(0.56,0.60]$ & $(0.60,0.89]$ & $(0.89,2.79]$ & $(2.79,15.34]$ \\
\hline \multirow[t]{2}{*}{$(0.170)$} & $\begin{array}{c}\text { 医院密 } \\
\text { 度 }\end{array}$ & $(0,2.21]$ & $(2.22,15.5]$ & $(15.6,31.3]$ & $(31.4,49]$ & $(49.1,80.6]$ \\
\hline & $\begin{array}{l}\text { 人均 } \\
\text { GDP }\end{array}$ & $(0,22684]$ & $(22684,27422]$ & $(27422,35549]$ & $(35549,49491]$ & $(49491,73406]$ \\
\hline
\end{tabular}




\section{3 洪涝灾害风险评价模型的建立}

根据自然灾害风险理论和洪涝灾害形 成原理, 综合考虑灾害风险形成的 4 个因 子以及相应的指标和权重, 将集对分析法 和可变模糊集理论相耦合, 计算危险性、 脆弱性、暴露性和防灾减灾能力 4 个因子 的评价样本等级特征值。在此基础上, 建 立城市暴雨洪涝灾害风险评价等级模型, 实现玉泉区暴雨洪涝灾害风险分析和区划 研究。

$$
F D R A=\frac{H^{w_{h}} \times E^{w_{e}} \times V^{w_{v}}}{1-R^{w_{r}}}
$$

式中, $w_{h}, w_{e}, w_{v}$ 和 $w_{r}$ 分别表示危险性、 脆弱性、暴露性和防灾减灾能力的权重, 表示灾害风险的形成因子的相对重要性。

\section{5. 玉泉区洪港灾害风险评价}

基于集对分析法和可变模糊集理论, 得到玉泉区各网格单元的危险性、暴露 性、脆弱性和防灾减灾能力等级特征值,

\begin{tabular}{|c|c|c|c|c|c|}
\hline $\begin{array}{l}\text { 等 } \\
\text { 级 }\end{array}$ & I & II & III & IV & V \\
\hline $\begin{array}{l}\text { 范 } \\
\text { 围 }\end{array}$ & {$[1,2]$} & {$[2,2.5]$} & {$[2.5,3.5]$} & {$[3.5,4]$} & {$[4,5]$} \\
\hline
\end{tabular}

根据各指标的 5 级分类原则, 则对应的评 价等级也将划分为 5 个等级, 分别定义 为: 极低、低、中等、高、极高。等级判 断准则如表 2 所示。

危险性方面主要考虑气象、地形和水 文等条件, 其中极端降水是引起洪涝灾害 的主要诱因。地形高程越低, 地形变化就 越小, 越容易受洪灾影响。地形变化引入 高程标准差, 其主要反映的就是一定邻域 内地形变化程度, 其中高程标准差越小, 地形变化越小, 表明该地区容易形成洪涝 灾害。河网密度可从一定程度上表征流域 的结构特征, 其与洪涝灾害危险性成正 比。由玉泉区危险性风险区划图 (图 2) 可 知, 极高和高危险区主要是位于研究区的
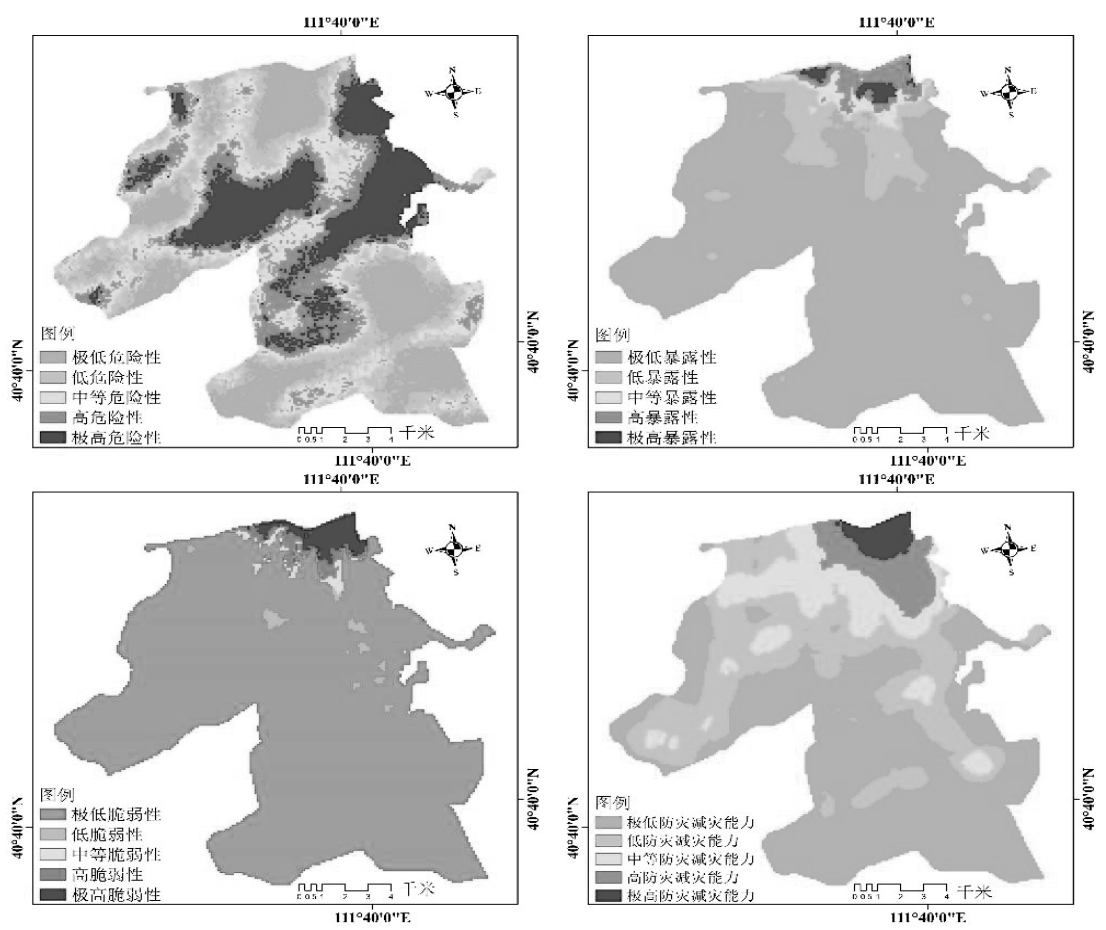

图 2. 玉泉区风险四因子区划图 
中部区域, 其中极高危险性所占面积占全 区面积的 $18.59 \%$, 所占面积比例为 $19.98 \%$, 主要是位于东北区域的南二环高 架桥附近、南湖湿地公园和大黑河附近, 高危险区也位于上述区域。而极低危险性 则位于西北地区和东南地区。

暴露性主要考虑的是社会经济因素, 其中人口密度越大, 洪涝灾害直接造成的 死亡人数、受伤人数及受到影响的人数就 会越大, 经济密度越高, 越容易受城市暴 雨洪涝灾害的影响; 因此选取人口密度、 经济密度作为暴露性指标。极高暴露性主 要是东北地区, 但是面积较小, 仅占研究 区面积的 $0.91 \%$, 而高暴露性与之毗邻, 所 占面积比例为 $2.96 \%$, 总体来说, 暴露性等 级由东北向南依次递减, 其中低暴露性等 级面积所占比例高达 $84.61 \%$ 。

脆弱性主要考虑的是灾害发生时造成 的人员伤亡和经济损失, 反应的是灾害发 生时该地区的脆弱程度, 因此选取中小学 校密度作为脆弱性指标。极高脆弱性主要 是位于东北地区, 所占比例为 $2.18 \%$, 主要 该地区紧挨赛罕区, 位于呼和浩特市中 心。

防灾减灾能力越高, 说明洪涝灾害发 生应对手段和处理时间越及时, 最终导致 的潜在损失就越小, 灾害风险也就越小。 在此选取路网密度、医院密度和人均 GDP 作为防灾减灾能力的指标表示地区防灾减 灾能力, 分布形式是有东北向东南递减。 极高防灾减灾能力所占面积仅为 $2.27 \%$, 位 于东北地区, 主要原因是高区域道路密 集, 人均 GDP 相对于其他地区较大, 并且 该地区医疗条件相对于其他地区有明显优 势。

在危险性评价、暴露性评价、脆弱性 评价和防灾减灾能力评价的基础上, 计算 洪涝灾害风险等级特征值, 根据风险等级 特征值的特点, 将风险等级划分为 5 级, 具体分级标准为: 极低风险: $F$ 值 $<3$, 低风 险: $3 \leq \mathrm{F}$ 值 $<5$, 中等风险: $5 \leq \mathrm{F}$ 值 $<7$, 高风 险: $7 \leq \mathrm{F}$ 值 $<9$, 和极高风险: $9 \leq \mathrm{F}$ 值 $<10$ 。 最后基于 GIS 得到了玉泉区洪涝灾害风险 评价等级图 (图 3), 实现了玉泉区洪涝灾 害的风险分析和区划。结果表明, 极高风 险等级区域主要是位于东北地区和中部地 区, 所占面积比例为 $3.86 \%$, 高风险区域所 占面积为 $7.16 \%$ 。主要是由于人口和经济密 度较高且距离大黑河较近的区域, 西部地 区和东南地区为低风险地区。

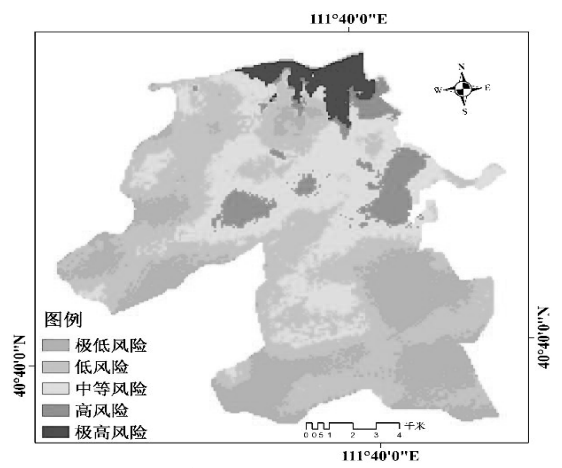

图 3. 玉泉区洪涝灾害风险区划图

\section{6. 结论}

根据自然灾害风险理论和洪涝灾害风 险形成原理, 从致灾因子的危险性、承载 体的暴露性和脆弱性、防灾减灾能力四个 方面出发, 构建了玉泉区洪涝灾害风险评 价指标体系。依据相关行业规范、规程、 标准以及玉泉区具体情况, 并结合相关文 献的研究成果, 制定了洪涝灾害风险评价 标准, 包括危险性评价、暴露性评价、脆 弱性评价、防灾减灾能力评价的标准。将 集对分析法与可变模糊集理论相耦合的方 法运用到洪涝灾害风险评价中, 能够较好 地处理风险评价指标信息的随机性和不确 定性, 通过相对隶属度函数对危险等级、 暴露性等级、脆弱性等级和防灾减灾能力 做出科学合理的计算, 并最终得到各评价 单元的风险等级, 结果表明极高风险等级 区域主要是位于东北地区和中部地区, 所 占面积比例为 $3.86 \%$, 高风险区域所占面积 为 $7.16 \%$ 。该方法提高了风险评价结果的稳 定性和可靠性。

\section{Acknowledgements}

This study was supported by the Science and Technology Development Plan projects of Inner Mongolia (No.201502095), National Social Science Foundation of China (No.41461101) and Science and Technology Innovation Guide Award Fund Project in Inner Mongolia $<$ Urban flood disaster monitoring and early warning management system development and product application $>$. 


\section{致谢}

本研究得到了内蒙古自治区科技计划项目 (201502095) 、国家自然科学基金项目 (41461101) 、内蒙古自治区科技创新引 导项目《城市洪涝灾害监测预警管控系统 研发与产品化应用》的资助。

\section{参考文献}

[1] 殷杰. 中国沿海台风风暴潮灾害风险评 估研究. 华东师范大学, 2011.

[2] 赵庆良. 沿海山地丘陵型城市洪灾风险 评估与区划研究. 华东师范大学, 2010 .

[3] 温克刚, 丁一汇. 中国气象灾害大典(综 合卷). 北京: 2008: 43-44.

[4] 张继权, 刘兴朋, 严登华. 综合灾害风 险管理导论. 北京: 北京大学出版社, 2012: 137-139.

[5] Fernandez E, Colubi A, GonzalezRodriguez $\mathrm{G}$, et al. Integrating statistical information concerning historical floods: ranking and interval return period estimation. Natural Hazards, 2012, 62(2): 459-483.

[6] Li Q. Fuzzy approach to analysis of flood risk based on variable fuzzy sets and improved information diffusion methods. Natural Hazards And Earth System Sciences, 2013,13(2):239-249.

[7] Ji Z, Li N, Xie W, et al. Comprehensive assessment of flood risk using the classification and regression tree method. Stochastic Environmental Research And Risk Assessment, 2013,27(8):1815-1828.

[8] Ruiz-Villanueva V, Diez-Herrero A, Bodoque $\mathrm{J} \mathrm{M}$, et al. Characterisation of flash floods in small ungauged mountain basins of Central Spain using an integrated approach. Catena, 2013, 110: $32-43$.

[9] Neal J, Keef C, Bates $P$, et al. Probabilistic flood risk mapping including spatial dependence. Hydrological Processes, 2013, 27(9SI): 1349-1363.
[10] Li Q. A Study on a New Method for the Analysis of Flood Risk Assessment Based on Artificial Neural Network. Advances In Computer Science, Environment, Ecoinformatics, and Education, PT 5, 2011,218:262-266.

[11] Li Q, Jiang X W, Liu D H. Analysis and modelling of flood risk assessment using information diffusion and artificial neural network. Water SA, 2013,39(5):643-648.

[12] Sun Z, Zhang J, Zhang Q, et al. Integrated risk zoning of drought and waterlogging disasters based on fuzzy comprehensive evaluation in Anhui Province, China. Natural Hazards, 2013: 1-19.

[13] 宋振华, 赖成光, 王兆礼. 基于集对分 析法的洪水灾害风险评价模型. 水电能 源科学, 2013(04):34-37.

[14] [邹强, 周建中, 周超, 等. 基于可变模 糊集理论的洪水灾害风险分析. 农业工 程学报, 2012(05):126-132.

[15] 纪婧怡. 面对强降雨, 大城市内涝频频 - - 以呼和浩特为例。商情, 2013(4):225-226.

[16] 吴成国，王义民，唐言明，等. 基于集 对分析的洪水危险性评价可变模糊识 别模型. 西北农林科技大学学报(自然 科学版), 2012(01):221-226.

[17] 陈守显. 水资源与防洪系统可变模糊集 理论与方法. 大连市: 大连理工大学出 版社, 2005.

[18] 孙仲益, 张继权, 王春乙, 等. 基于网 格 GIS 的安徽省旱涝组合风险区划. 灾害学, 2013(01):74-78. 